\title{
Documentos sobre las Gestiones del Cacique Tupac Amaru ante la Audiencia de Lima
}

\section{(A LA UNIVERSIDAD DEL CUSCO)}

A fines del año 1777, el cacique de Pampamarca, Surimana y Tungasuca don José Gabriel Condorcanqui Noguera o José Gabriel Túpac Amsru, salió del Cusco con dirección a Lima. La finalidad de su viaje era doble: de una parte, litigar contra los Betancourt sobre legítima descendencia del inca Túpac Amaru (ajusticiado por el virrey Toledo en 1572); de la otra, gestionar que los indios de la provincia de Tinta lo Canas I Canchis) fuesen exonerados de servir en la mita de Potosí.

El Cacique elevó un recurso con-fecha 22 de julio de 1777, recibiendo la contestación del visitador Areche el 23 de septiembre del mismo año (véase parte de la respuesta de Areche en la "Guerra Separatista" por Luis Antonio Eguigtrenge Impccionresi Aguirererlima, 1942, pp. 10-13). El 18 de diciembre de 1777 el cacique Túpac Amaru elevó un nuevo recurso (Eguiguren, ob. cit. pp. 14-18). De lo ocurrido con posterioridad, el autor citado trae unas líneas breves, aludiendo a lo acaecido desde esta fecha hasta mediados de 1778, momento en que Túpac Amaru se vió obligado a retomar a su provincia de origen. Por eso, aquí se insertan aquellos papeles omitidos, así como parte del recurso inicial de 22 de julio de 1777, documento que tampoco se encuentra en la obra del Dr. Eguiguren.

Los documentos que se publican me fueron facilitados por el doctor José M. Valega, en 1943, habiendo sido copiados de unos manuscritos pertenecientes a la antigua Biblioteca Nacional de Lima. Esto está de acuerdo con lo escrito anteriormente por el Dr. Equiguren (ob. cit. pp. 19, nota 1). Afirma éste, cómo los documentos que publica (en estrachísima relación con los que aquí se insertan) pertenecían a la Sección de Manuscritos de la Biblioteca Nacional de Lima, No 0017, habiendo Sd- 
cado copia en la época que estaba de Director el integérrimo don Manuel González Prada.

En lo que sigue insertamos ocho documentos, referentes a las gestiones del cacique Túpac Amaru ante la Audiencia de Lima, entre modiados de 1777 y mediados de 1778: 1) Recurso de Túpac Amaru (incompleto) 22-VII-777, 2) Traslado del Fiscal Protector General e Informe del Contador de Retazas 8-VIII-777, 3) Auto del Fiscal Previsor General 9-IX777, y anotación marginal 12-IX-777, 4) Dictamen de Areche 25-IX-777, 5) Otro Recurso de Túpac Amaru 18-XII-777, (que puede servir para reconstruir el primero, del mes de julio), 6) Respuesta de la Contaduría de Retazas 7-1-778, Traslado del Protector General 7-IV-777, y del Protector General Interino 30-IV-778, 7) Auto del Oidor Fiscal 9-V-778, y 8) Poder dado a Túpac Amaru en el Cusco 4-X-776.

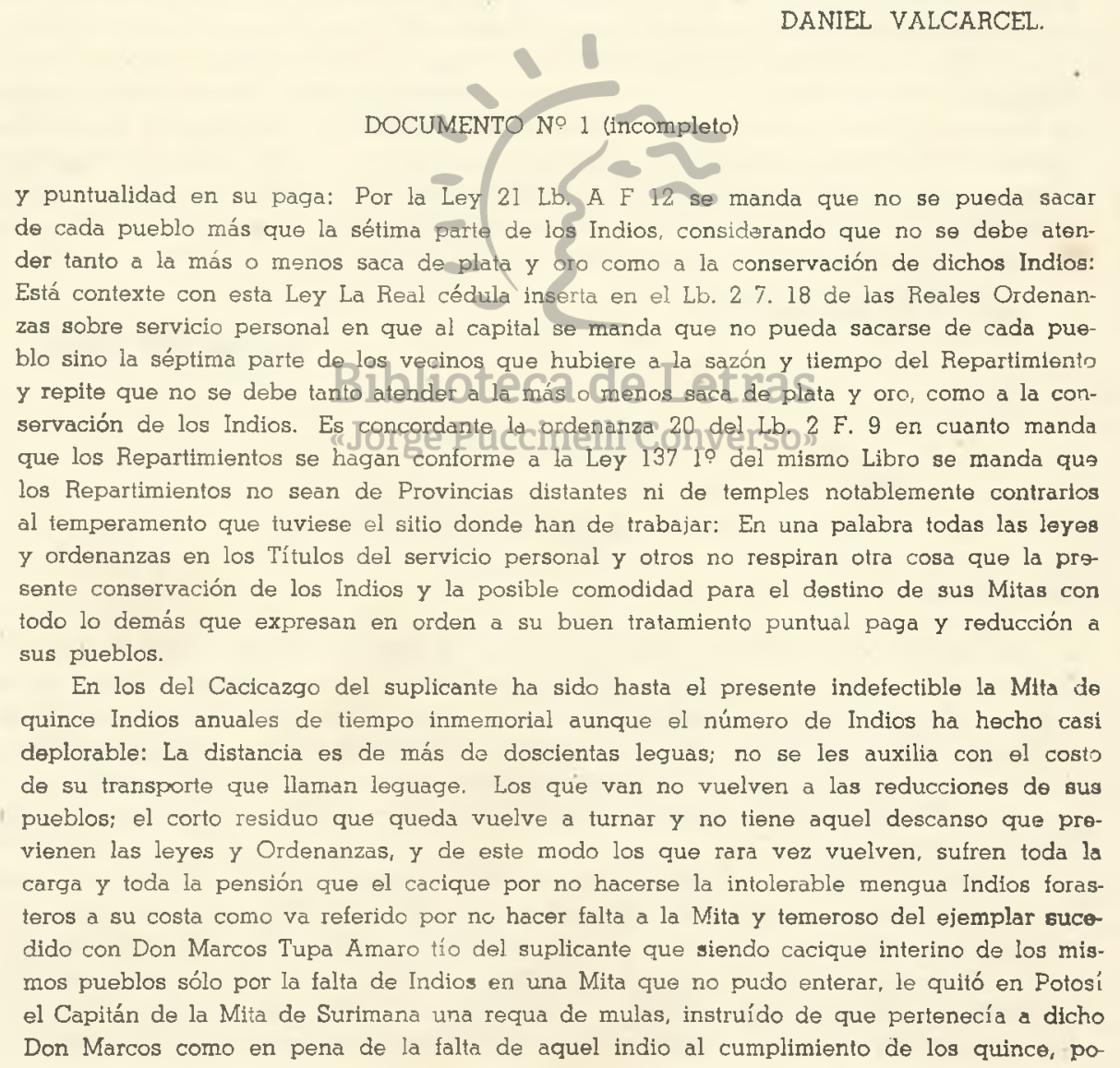


niendo a sus peones a la panadería: Esto sucedió en tjempo que era Corregidor de dilcho Provincia Don Gregorio Viana que actualmente reside en el Cuzco, y todo se quedó perdido, aunque las leyes y ordenanzas prohiben que a los caciques no se les condene on pena pecuniaria por defectos de cumplimiento en la Mita aún cuando le fuese culpable. y no por la justa causa de no haber Indios.

Ultimamente ya han llegado a aquellos pueblos al extremo más miserable y no es posible la pensión de la Mita porque prescindiendo de la gran distancia, de la falta de avíos de la diversidad de temperamentos y demás inconvenientes expuestos no hay ya Indios, y si los pocos que quedan se van a Potosí dejaran de ser, pueblos los de Surímana, Pampamarca y Tungasuca, y sólo quedaran hechos un monumento lastimoso con perjuicio de la Real Corona que pierde la conservación y el aumento de aquellos tributarios, y más en tiempo en que ha cesado el motivo con el numeroso vecindario de Indios que notoriamente se han congregado on Potosí.

Y, ya al suplicante por obligación y por lástima le es indispensable este recurso porque en los Indios de los dichos pueblos es raro el que no haya hecho dos Mitas que es el clamor más sensible por la distancia y por el tiempo que gastan en ir y volver los que por fortuna vuelven, ni el suplicante tiene facultades para mengare otros Indios forasteros. ni para pagar los tributos de sus pueblos todo lo que se hace digno de la piedad y justificación de V. E.: Por lo cual a V. E pide y suplica se sirva libertar dichos pueblos de la Mita de Potosí, atenta su notable decadencia, perjuicio del Real interés de Su Magestad y demás graves inconvenientes expuestos que llevan a la total desolación de dichos pueblos contra las Reales intenciones de Su Magestad y jura el suplicante a Dios Nuestro Señor y a esta señal de la Cruz $\neq$ ser cierta y verdadera esta relación en justicia que pide Y espera alcanzar de la notoria benjgnidad e integridad de V. E.

Lima, 22 de fulio de 1777.

\title{
Biblioteca de Letras

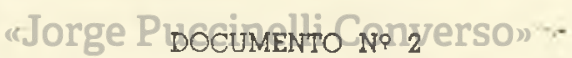

\author{
Informe el Contador de Relazas
}

Excmo. Señor:

El Fiscal Protector General. Visto este recurso de Don José Gabriel Tupac Amaro, Cacique de los pueblos de Pampamarca de las Provincías de Canas y Canchis, sobre que ere redime a los referidos pueblos de los quince Indios que se sacan actualmente para la Mita de Potosí: Dice: Que siendo V. E. servido podrá mandar Informe sobre el particular el Contador de Retazas y especialmente sobre si este número de Indios Mitimayos corresponden a la séptima parte de que deben reducirse; y que hecho corra el traslado, o lo que sea más de justicia.-Lima.

Retazas de este Reyno en vista del antecedente reprsentación interpuesta por Don José Tupac Amaro cacique principal que dice ser de los pueblos de Pampamarca, Tungasuca y Surimana, del distrito de la Provincía de Canas y Canchis (Alias Tinta) sobre que se exonere y líberte a los Indios de ellos de la obligación en que están de concurrir al trabajo de las Mitas de Potosí, ya por el malirato que reciban de los mineros de su rivera y ya poser este destino el principio de su ruina y la desolación de sus reducciones y orígenes. 
Lo que se debe informar a V. E. en conformidad de lo mandado en su Superior Decreto de 22 de Julio próximo pasado, proveido a pedimento de los Señores Fiscales, se reduce a que siendo esta materia tan profunda y obscura como su mismo objeto, según la estima el mejor Senador Político por la diversidad de fundamentos con que por una parte se apo. ya lo justo y necesario que es el Repartimiento forzado de los indios Mitimayos para el laboreo de las minas, y por otra lo que le convencen de injusto y temerario, autorizándose de ambas con la Real Disposición que por la afirmativa y rogativa se compilan en los cap:tulos 15 y 16 del Libro $2^{\circ}$ de la Política Indiana: Expondré en ella sin desviarme de su principal nervio lo que puede conducir a el libro de los Indios a que siempre propende la piedad del Rey, y a que no descaezca el fomento de este trabajo de las minas como bana on que estriba la conservación del Reyno y su prosperidad, o por decirlo de una vez de toda la monarquía, en fuerza de las utilidades físicas y naturales que redundan en beneficio de los vasallos, de que se deben contemplar partícipes los Indios pues distrutan este título, para ayudar a cuanto contribuya a su mayor auge.

La obligación que hoy tienen los Indios de asistir al trabajo de las minas, no es nueva, sino que viene derivada desde el tiempo de su infidelidad, pues los Incas y Montesumas que entonces los señoreaban (o por mejor decir los tiranizaban) aplicaban a este destino un crecido número, y así el permanecerlos en esta costumbre es fundamento poderoso para no considerarla en lo absoluta dura $y$ honerosa como gravamen de que han estado siempre atectos si se la ha permítido después de un sumo cuidado $y$ estudio con que en sus Reales Consejos se ha tratado esta materia aprobando enunciativa y dispositivamente el servicio $y$ Repartimiento de las Mitas para el laboreo de las Minas, interín el tiempo descubría medios y arbitrios que lo facilitasen de modo que dejasen a los Indios en algún desahogo y alivio. En lo que lo que hace más gravoso es la no observancia de las Reales decisiones relativas al buen tratamiento que se les había de dar pionta paga de sus jornales en plata y mano propia, anticipación de los leguajes antes de que salgan de sus pueblos y tantas distancias a que se les destina en lugares de temperamentos tal vez contrarios al de su origen $y$ naturaleza.

De este principio hace, que los Indios vivan exasperados con el servicio forzado de làs Mitas, al tocar también cōn la experiencia de que el desengaño de que es igualmente el de su ruina, pues regularmente mueren muchos en la penosa tarea de Minas; $y$ aunque es verdad que el Excmo. Sr. Toledo estableció las Provincias que habían de mitar a los minerales de Huancavelica y Potosí que distan de ellas doscientos y trescientas leguas, lo que en aquellas circunstancias pudo ser necesario para fomento del Reyno por estar en los primeros pasos de su conquista, no lo es ya al presente por la propia alteración que causan los tipos que por si piden torzada variedad para evitar mayores daños y perjulcios.

Poco o nada ignorados son los que les infieren los mineros a los Indios sin que a su. remedio vaste el más fervoroso celo de los jueces para propender a el cumplimiento de la Iey o la Ordenanza, que prohibe y manda castigar los excesos que con ellos se cometan. sirvióndoles de broquel y escudo las mismas distancias para que no puedan ser oídos los jemidos $y$ quejas.

Por esta razón se reclama comúnmente sobre el Repartimiento forzado de los Indios a las minas. No trata el Contador de Rentas de persuadir que este absolutamente se extinga porque conoce y bien la decidia y flojedad de esta nación al trabajo lo que importa al Reyno el fomentos de los Minerales de su distrito, en que se interesan las dos repúblicas ya unidas de Españoles e Indios, y el que dejándolos en libertad vendrán a notable detərjoro; pero si, de que se les modere esta carga, sujetándola a los términos que previenen en las mismas leyes, y a que se pongan en ejecuciones los prudentes arbitrlos contenidos 
en el capítulo 17 del cilado L.b. $2^{\circ}$ del Sr. Solórzano sin que se tengan por difíciles en su ejecución porque las más veces la falta de determinación las hace más, cuando el mismo tiempo puede irios ajustando y facilitando, según doctrina de algunos AA y de lo contrario será necesario que la Divina Providencia provea a este Reyno minas, de Indios, del mismo modo que de metales pues la experiencia nos va acreditando que contínuando el Repartimiento forzado de las Mitas del Potosí y Huancavelica, en la propia conformidad que se ha observado y observa; desde luego llegará a conseguirse esta Nación según el crecido número que muere en el servicio de ellas.

El origen de este daño, y no distante temor estriba en no observarse lo dispuesto por la ley $3^{4}$ título 12 del libro 6 ? que previenen que los Indios no miten a más distancia que de diez leguas y la 29 del propio título y libro para que no se repartan a diferentes temples opuestos a su naturaleza lo cual y el sacarlos de sus casas distan largas distancias, les hace más penosa la mita como es regulâr; y por esto con este conocimiento tiene S. M. dispuesto por la ley 17 del título 15 Lib. 6ํ que en la Comarca de Potosí y en las demás labores de este género, se hagan Poblaciones de Indios para el servicio de las mismas excusándose de este modo el iraerlos de fuera con lo que también concuerda el capítulo 49 de la Real Cédula expedida el año de 609 que trata del servicio personal pues en él se ordenan que se hagan reducciones. Poblaciones de Indios en los mismos asientos de Minas en $\in I$ número que pareciese bastante, para que solo éstos y lo que de ellos se fuese procreando se ocupasen en su labor y beneficio.

Con éstos se puede hacer sin especial gravamen el trabajo de las Minas, destinando el número de forzosa obligación, que corresponden en su 7 ? consultando a el remediu de su natural desidia y tlojedad, y a él concurrirán los que voluntariamente se apliquen, pagándoles bien su jornal en plata, y mano propia como sucede con los que se alquilan o... de su voluntad en las minas de Potosí y Huancavelica de este Reyno y en las de San Luis, ... y Pachuca de la... donde no se oye declamar tanto sobre este servicio.

A más de estos fundamentos sobre este servicio más poderoso para que no continíse el Repartimiento de las Mitas de Potosí y Huancavelica de las remotas y distantes Provin cias, en que lo dejó establecido el Sr. Toledo, y es el que los mineros contravinienuo el tenor de la ley $7^{a}$ del dítulo 19 libro $6^{\circ}$ que previene que,no reciban plata de los Indios، por escusarlos de la Mita, lo ejecutan así generalmente pretestando que con lo que contribuyen menguan, alquilan otros... de la misma Rivera. Sobre lo que es de notar que no hay especial necesidad de trabajadores que habían de venir de fuera, $Y$ todo el objeto es sacarles el dinero que hacen con el fruto del sudor de los Indios; el trabajo (si llega a verificarse, y no lo convierten en otros destinos, siendo esta su mejor.... de que no la redunda al Rey la menor utilidad, de suerte que por esta causa debe cesar tambtén el mencionado repartimiento, y a ello influiré igualmente la decadencia a que han venido dichas minas no por falta de operarios, sino por la corta ley de sus metales. Otros muchcs minerales hay descubiertos dentro las mismas Provincias y tanto más ricos y abundantes que se hallan sin fomento y labor, porque no se les asiste con gente, respecto de pasa? su 7o a los dichos de Potosí y Huancavelica, y destinándose a ella los que tenían esta obllgación, convalecerá el Reyno de posibilidades y de Indios, dándose cumplimiento a las le. yes $y$ a citadas, que ordenan no salgan de sus orígenes $y$ a largas distancias.

Y cuando sea necesario mayor número de trabajadores, sería muy conveniente, sin distinción de clases, ni castas como lo siente el Señor Solórzano, en el capítulo 17 ya citado de su Política, con lo cual se lograría el fomento de las Minas sin que sólo los Indios fuesen los que por su mansa, y rendida condición sobrelleven este peso, y las demás naclones disfruten el fruto de su sudor: y al mismo tiempo servirá a dichos delincuentes esta 
aplicación de freno, para que no se cometiesen tantos delitos y se limpiase el Reyno ds los muchos aciosos, vagos y lacinerosos que lo radean purgando sus excesos con utilidea pública y por este medio descansarán, y aún entrarán los Indios para que ayuden en dichos servicios que no sean tan laboriosos.

Para esta plantificación y establecimiento que no es de considerar de mucho arbitrio ni tampoco distante de las Reales intenciones de S. M. pues en cuantas leyes y cédulas ha expedido manifiesta que el Repartimiento forzado de los Indios en la confornidad que lo dejó establecido el Sr. Toledo, y continúa, es sólo tolerable, y lo permite interín el tiempo descubriría dichos arbitrios, y modo de trabajar las minas, no puede presentarse otro más oportuno que el presente, en que se trata de reducir este Reyno a sencillas y seguras re. glas para su manejo con un Señor Visitador que ha nombrado S. M. de notoria inteligencio. acreditada prudencia y demás con principios proporcionados a tan loable fin: El Contador da Rentas le ha oído repetidas veces declamar sobre este punto con íntimo conocimiento de que el desorden que hay en ello por las faltas de cumplimiento de las leyes, y ya por los abusos, que ha introducido la malicia y codicia de los Mineros, va conduciendo al Reyno a su perdición por la decadencia de su principal República indica en acuerdo tomar la resolución más conveniente: $Y$ en cuanto de lo particular de la Mita que habían de contribuir a Potosí, los expresados pueblos de Pampamarcã, Tungasuca y Surimana de la Provincia de Tínta, respecto de corresponder a siz 79 no sólo los quince Indios que expresa el supitcante, sino algunos más según los empadronados en el último reconocimiento y escrutinio que de ellos se hizo; expedir igualmente la Providencia que exprese de su superior agrădo. Contaduría de Rentas y agosto 8 de 1777.

Excmo. Señor:

(do.) Juan José de Lemos.

El Fiscal Provisor General vista la representación de Don José Tupac Amaro caciqua principal de los pueblos de Pampamarca, Tungasuca y Surimana de la Provincia de Canas y Canchis sobre que se exonere a los Indios de ellos de la obligación en que están de cor. currir a las Mitas de Potosí: Dice: Que aunque S. M. siempre ha propendido a abolir estas mitas permitiéndoles sólo en los casos indispensables y forzosos en que se interesa el pú. blico, y de que resulte el beneficio, pero debe de considerarse de primer orden el privilegio de las minas que tanto se recomienda por el Soberano en sus leyes y Reales Cédulas. La de Potosí es la que más utilidad ha dada à S. M. y debe tomarse mucha consideración a que subxista y no descaesca por falta de operarios que la trabajen. Los que sólo podrán eximirse en el cáso de que no sean precisos. El pensar si hay o no al presente necesidad es materia de mucha gravedad; y así siendo V. E. servido podrá resolver este punto con consulta del Señor Visitador General o si le pareciere reservar la resolución para cuando se concluya la de los tributos de que se está tratando, pues es regular que verificada proceda dicho Señor Visitador por la conexión que tiene a tomar providencias sobre Mitas. Lima, y setiembre 9 de 1777.

(Al margen dice así): Lima, 12 de Setiembre de 1777. Para dar la resolución que corresponda con acuerdo del Señor Visitador General del Reyno como pide el Señor Fiscal: pásesele inmediatamente este expediente. 
FOLIO 164

Lima, y setiembre 25 de 1777.

\section{Excmo. Señor:}

La solicitud que contiene este expediente se reduce a que los Indios de los Pueblos de Pampamarca y Tungasuca en la Provincia de Tinta no estén obligados, por les razones que se expresan a dar trabajadores para la mina de Potosí.

Este solicitud se hace porque el que se titula su cacique, sin instruírlo sentando que es uno de los motivos principales por que ha llegado a esta capital tampoco instruye el despacho en cuya virtud se piden los Indios de Mita ni otras circunstancias, que no serían impertinentes para dar la resolución sin miedo o recelo de no otorgarla e ilegítima parte, y todo se debe reparar en estos asuntos no sólo por su materia que es acto grave, y acaso de las más necesarias de remedio sino porque lo pide así la seriedad de cualquiera determinación y los antecedentes que deben concurrir a formarlas.

Sentadas estas dos partes diré alguna cosa sobre las razones en que se funda la pre. tensión de que estos Pueblos se les liberte de mitar que es la primera, y luego trataré a lo que se pueda resolver, aunque bien diminutas, en la segunda parte.

Las leyes de Indias han querido que sus primeras Naturales no estén ociosos más de lo que exige la naturaleza para un descanso legítimo, racional y propio: A este fin encargan que se apliquen a las Minas y a las Haciendas llamando a los primeros Mitayos y a loz segundos Yanaconas, si en esta aplicación de Indios al trabajo hubiera el curplimiento do el espíritu de las leyes sería justo seguirlos sin recelo alguno pero puede más que la ley el exceso o práctica a que se ha traído dolorosamente su mandato $y$ con especialidad en este Reyno: En el de Nueva España se reparten algunas veces, aunque pocas, Indios a las minas; pero en su cuanto y en su distancia, están cumplidas, hasta con escrúpulo, las mismas leyes; nunca se excede en el número de cuatro por ciento, ni nunca de la distancia - circunlerencia de diez leguas Opero aquí, cen cuanto à esfa última parte, es enorme y espantosa por lo retirado de los pueblos a quienes se piden y reparten los Indios en Mita.

Hace horror que se lieven a esfos infelices a vencer doscientas, trescientas y más lo. guas para trabajar después en una Mina como la de Potosí, u otra según se practica on esta América: Cansados del camino poco trabajo pueden hacer útil, o han de descansar algunos días para hacerle: Doy de barato como se suele decir, que se les pague los días de camino desde el día en que salen de sus pueblos hasta el día en que vuelven a entrar. que harto difícil se me hace de creer, y aún se queja el Cacique de esta solicitud; es posible que no pensemos en que naturalmente hay repugnancia $y$ disgusto en ir a rendir estos tra. bajos, aunque fuesen más ventajosos que son para ellos, a tanta distancia separándose do sus familias, y de sus pueblos que es fuerza amén por una Ley secreta y poderosa que hay en todo viviente? En este tiempo abandonan sus casas, dejan sus bienes o Ranchos, pierden de vista a sus amigos y socios, a su Párroco, a su justicia, y a su temperamento, que es lo que con preferencia vić la Ley para que no se les llevase ni trajese a las distanclas que les pudiesen ser ofènsivas.

La Mita según se practica en el Reyno es a mi entender uno de los males que es fuerza cortar brevemente, si queremos Población, habilidad, y que se nos acerquen los Indios a lo que deben o pueden ser. Nosotros los conquistamos para el buen trato, para pro vecho a sus almas, para hacerlos civiles, y con aquellos bienes y dotes naturales on usi que no tenían en su gentilidad. Procuramos rectificar su procreación, sus costumbres, y 
cuanto merece la naturaleza del hombre con el cumplimiento de las Leyes Divinas, Eclo siásticas, Politicas, y Morales, enseñándoselas pausada y dulcemente; pero no hallamos los progresos que corresponden a la acción, y acaso, y sin acaso, es por lo que adelantamos o queremos adelantar con una mano peredmos con la otra; quiero decir que no están completos los medios o las reglas; ni armoniosa la acción para lograr, todo el bien. Los Indios pasan después de conquistados, o del mismo punto a nuestra sociedad, pero si es pesada como parece que la conciben, poco adelantaremos. Salen de la libertad natural a la sujeción civil, y si ésta pasa de sus precisos límites degenera o es fácil que degenere en esclavitud. En la rudeza de su antigua vida poco o nada echavan de menos; en la Política y cristiana advierten y experimentan cosas, que porque desconocen y desconocerán por m: chos ellas su objeto de les hacen pesadas. Gran tino y cuidado debe haber en el Gobierno para conducir esta clase de Vasallos, pues que queremos con tanta necesidad y obligación el hacerlos útiles. Su estirpe o clase está llena de Privilegios por las Leyes, pero pocos efectos de ellos logran, o pocas veces los disfrutan con la franqueza que se les declaran: En el Indio debemos poner el buen trato por muchas razones, unas miran al cumplimiento de la Legislación Política y Cristiana, $Y$ otras el adelantamiento de la conquista espiritual y temporal: Si no tratamos bien a los conquistados se hace muy difícil o casi imposible que vengan a vivir con nosotros los gentiles; éstos, interín lo son, se pueden ten ir por enemigos, y aún después tardan mucho en ser de nuestra amistad; el ejemplo es poderoso en todas las cosas, y si es malo, hay pocos medios que le hagan contra resto, y más en la clase de gente de quien estoy hablando. La noticia de lo que padecen los Indios contra las intenciones del Gobierno y de la Ley transmigra hasta lo más escondido de los Aduares, o Ranchos de los Gentiles; allí se considera lo que sufren los conquistados, y lal vez se le dá el mal colorido de tiranía en su idioma. Penetran a sus chozas o paizos pocas o ninguna noticia del adelantamiento de los Conquistados; y éstos los ponen en más precisión de hacernos la guerra y de huir de nosotros: Alguna vez he dicho hablando de este asunto, en las muchas que lo he hecho en la otra América, como Fiscal, que se deben haber perdido los medios con que al principio fué feliz $y$ próspera la conquista. como que entonces abrevianos en üncótisino período de tiempo más que hemos adquirido después de un fuerte número de años; también he dicho que esto puede pender de que - no son nuestros actuales "misioneros def tervor, espiritu, Y afán apostólico, que fueron los que en aquellos instantes hicieron tantas ventajas o de que nos hemos desviado de su método de catequizar; o de que no tienen hoy tan buena armonía las dos conquistas es piritual y temporal que se hacen unidamente, queriendo que sean los gentiles tan pronto como vasallos cristianos; y tan pronto como la dominación de nuestros Ritos y Dogmas católicos. Lo que se desea y procura es bueno; el medio de desearlo es el que padece alguna alteración sensible y dolorosa.

En la otra América a instancias mías y de la soberana piedad y religioso espíritu del Rey, se queda tratándo este asunto con el mayor cuidado y creo que Dios ha de ver alli. y aquí esta causa como suya, si nos conserva, así como en el rectísimo corazón de S. M. en el de sus Ministros y Gobierno el vigor y diligencia con que ha mandado tratar ests asunto de la mayor importancia para la religión y para nuestro estado. Echemos la vista a cualquiera de las partes donde hemos querido plantar y hemos plantado la Fé de Jesucristo y su Iglesia Santa, y hallaremos que siendo, al entrar numerosísima la gentilidari se nos desaparece luego de entre las manos como nos solemos explicar; este desapareci miento tiene muchas causas, algunos pueden descender de la diversa vida y trabajo en qua entra el neófito o catecúmeno, y otras de la fuga o internación que hacen a vivir con los gentiles más separados, o de la que emprenden vagando fuera de sus Reducciones contra 
el espíritu de las Leyes, que tanto encargan a sus inmediatos Gobernadorcillos y Justicias la restitución como se puede ver en la 13 y 18 de este título.

Paréceme que me he alejado mucho del punto de la Mita que es el que mueve esta expediente, pero según mi opinión estoy dentro de él, y digo que esta y los malos tratamientos que reciben los Indios son causas parciales y acaso algo más para que los Naturalea vayan cada día a menos, para que no tengamos tantos como tuvimos, y para que no prospere tanto su extirpe como quieren las Leyes, y los Ilustrados Gobiernos de nuestra na. ción y el que lleva V. E. con tanta heroicidad, vigor y rectitud en estas provincias, que la incomparable justificación del Rey le tiene fiadas, para señalar en estos vasallos $y$ in estas tierras el amor, cuidado, y atenciones que le merecen desde el trono y con especialidad a los indios en que todos los demás Convasallos tenemos un interés de primer orden y un bien de la primera necesidad.

El Repartirniento de los Corregidores, los dineros Parroquiales, los servicios involuntarios, y otras mil cosas que sufren por no sujetarse los que la cometen al espíritu de lit Ley, tienen a los Indios en el estado en que se ven, pero en el Rey y en V. E. en au nombre, hay vigor, hay justicia, $y$ hay felices disposiciones para tomar y disponer algunos de aquellos suspirados Decretos que pueden interrumpir este mal y acaso extinguirlo on mucha o en la mayor parte con el tiempo; con que ganará mucho el Estado, los Naturales y la Real Hacienda en los tributos de que ya se apunta lo bastante.

Sentado pues lo que juzgo acerca de la mita de que se quieren libertar los Indios de esta solicitud, si se hace por ellos según es de entender, bien que ya dejo dicho que no so instituye como corresponde, y convendría hacerlo en otro caso voy a dar razón de la Nota que puede tener su escrito en la forma explicada.

El largo tiempo que he servido en la otra América me ha hecho ver que muchas veces se pide por los Indios o a su nombre en los Tribunales Superiores aquellos de que no tienen necesidad, conducidos del interés con que sus Caciques o Gobernadores los meten en las solicitudes y les pintan las ventajas que lograrán conseguidas que sean; Para esto por la natural inquietud $\mathrm{Y}$ afición con que ve el Indio toda clase de libertades $\mathrm{y}$ li. tigios, se les echan derramas o contribuciones a que seprestan prontos, y vienen de aquí, las más veces, el sufrirlas, hacer gastos inútiles, y no avanzar o conseguir sus deseos, saliendo solo aventajado "el que disirufa la derrama. Por esto $Y$ "por algunas otras razones en que no me quiero detener, he reparado que ni el cacique que representa sobre la relovación de la Mita acompañe poder u otro documento con que se le pudiera tener como legítima persona, para pedir, ni tampoco se sabe si toca a estos Pueblos el dar la gente que se dice que les cabe para la Mina de Potosí.

En este supuesto, y que no es fácil cortar de una vez los grandes males que trae la Mita a los Indios, porque sería peor el remedio que la enfermedad y así se hiciese hoy, atendidas todas las circunstancias que se deben atender, y que este punto es uno de los encargos que me ha fiado $S$. M. en el artículo AA de su Real Instrucción reservada, y tendrá sus resoluciones particulares cuando llegue a él con todo el examen necesario, pueds V. E. remitir este recurso en testimonio al Sr. Don Jorge Escovedo Ministro de la Reai Audiencia de Charcas para que como que acaba de poner el Rey a su cuidado el Corre. gimiento de Potosí, y demás incidentes de aquel mineral, y entre ellos la Superintendencia de Indios Mitayos tome en su asiento la providencia que regule oportuna en lo pronto haclendo que, si a los Pueblos por quien se habla en el anterior escrito, se les reparte Mila se les pague las leguas del viaje con todo el escrúpulo que previene la Ordenanza del Reyno, $y$ las Leyes, que no se les haga trabajar más que lo justo en la Mina, ni se les den malos tratamientos a éstos, y a cuantos vayan de otras reducciones, y que se deja al ceio 
de Su Señoría, y a las demás providencias que tomará por su cargo, el ver este punto de. Mita con toda reflexión que pide en favor de la Minería, en favor del Estado, y en favor de los mismos Indios que asisten o deben asistir a su labor y que igualmente s; espera que disponga que ésta la lleven en el todo si es posible los que no vivan tan separados como los de esta solicitud, ni los de las Provincias muy distantes, haciendo que entre a trabajar y ocuparse en este entretenimiento la mucha Plebe de que abunda hoy en Potosí, según se afirma, para quitar de este modo los abusos del rescate de Mita, y algunos más de que hay noticias seguras de que hacen este mal más insoportable y trisie allí, y en otros Minerales donde hay esta saca de Indios.

Tomada la resolución que cuerde aquel Señor Ministro en este particular caso se j? puede: encargar que sobre el punto en general extienda su Dictamen y le remita a in de que se vaya meditando y viendo aquí este despacio según conviene con todos los respectos $Y$ partes que incluye $Y$ se traerá Su Señoría a la vista.

Al Cacique que representa se le dirá que su escrito no trae la Instrucción que era necesaria para hacer el recurso de la relevación de Mita que se pretende; y que así so retire a sus pueblos por ahora, esperando allí la providencia, que no obstante, dará desde su destino el Sr. Superintendente de la Mita, a quien se remite por el correo, como qus será la más arreglada a la distancia de estos Indios, tocándoles el dar gente, y a las demás razones con que desean libertarse de ir a trabajar a las minas de Potosí; o a que sa les pague con preíerencia, y el resguardo oportuno, los salarios del camino de ida y vusita, según es práctica y encargo estrecho de las Leyes, y Ordenanzas de esta Amérlca.-Lima, setiembre 25 de 1777.

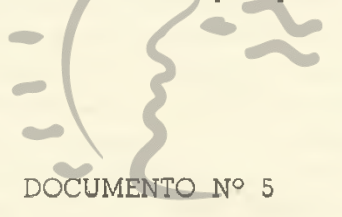

(fdo.) Areche.

FOLIO 169

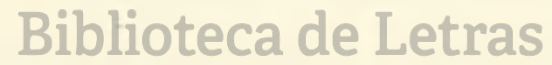

Inlorme el contador de Retaras, y vista a los Señores Fiscalea

Lima, 18 de Diciembre de 1777.

\section{Excmo. Señor:}

José Tupa Amaro, Cacique de los Pueblos de Surimana, Pampamarca y Tungasuca en las Provincias de Canas y Canchis (alias Tinta) en nombre de los caciques de los demás pueblos de dichas Provincias $y$ en virtud de sus poderes que en debida forma present:a puesto a los piez de V. E. con su mayor rendimiento dice: Que el suplicante por lo respectivo a sus Pueblos hizo a V. E. la más humilde representación a beneficio de aquellos Indios que le son sujetos por los imponderables trabajos que padecen con la Mita de Potosí en uns distancia de más de 200 leguas, y lo que es más el gravísimo daño de la extirpación d: los pueblos en el visible experimental de sus Indios que obligados a una Mina de tan con siderable distancia cada uno carga con sus mujeres, y con sus hijos, y hacen una doloros $x$ despedida de su patría, y de sus parientes porque la rigidez, y la escabrosidad de los ca minos los mata, los aniquila el extraño temperamento y pesado trabajo de Potosí, o su ir.digencia no les dá arbitrio para regresar a sus pueblos cuando la calamidad no ha acabado antes con su vida. 
Los demás Pueblos de la Provincia padecen igual infeliz suerte y todos claman por el alivio de una insoportable pensión, siempre ha sido grande pero en los primeros tientpos era multiplicado sin comparación el número de Indios, y podía turnar las Mitas con alguna tregua, $y$ con algún descanso. Sucedía entonces lo que hoy sucede pero de diversa manera. Entonces morían los Indios y desertaban, pero los Pueblos estaban numerosos, $y$ se hacía menos sensible su falta; hoy en la extrema decadencia en que se halla, llega a tocar el imposible del cumplimiento de la Mita, porque no hay Indios que la sirvan, y es necesario que vuelvan los mismos, o que los caciques allanen la voluntad de dichos forasteros para que la completen pagándoles de šu dinero el importe en que se ajustan.

Enlonces van por escasez de gente a trabajar en unas Minas ricas, y a sacar sus metales en beneficio público, y hacian el servicio del Rey como sus humildes vasallos en asunto de tanta importancia a la Keal Corona y al Reyno; hoy llenos de miserias van a servir a los que sólo tienen el nombre de Mineros que en su deficiencia de metales hacen granjerías de la Mita, alquilando a otros los Indios de su Repartimiento u ocupándolos en escojer metales de la broza que llaman aventurar en que después de ser prolijo el trabaio los obligan a cumplir con la tarea del mismo modo que si estuviesen prontos los metales para cargarlos, de manera que la tarea de un día apenas la pueden ganar en tres.

La atención de $\mathrm{S}$. M. benignamente manifestada en sus multiplicadas leyes, $\mathrm{Y}$ ordenanzas no es otra que la dei buen tratamiento y conservación de los Indios. Aún en el punto de Mitas se hace preferente en Su Real piedad comparada la utilidad de la saca de los metales, y extracción a sus riquezas, porque poco importarían éstas, si la extinción de los Indios las podía hacer poco duraderas porque faltando aquéllos, faltarían tambión éstas. La necesidad hizo oportuno, y de menor inconveniente el auxilio de la Mita, interin poblado el cerro de Potosí, podía proveerse de trabajadores, sin la pensión de ocurrir por ellos a Provincias remotas como es la de Canas y Canchis que dista más de doscientas leguas de Potosí. Considere V. E. qué tornada esta, y qué caminos para transitarlos a pie como lo hacen estos miserables Indios. Ya se deja ver cuanto sería su trabajo, su incomo. didad, y su molestia.

A más del tiempo que gastan en la jornada llegan ya destroncados incapaces de suírir la dureza de la labor déla Mina. Puccinelli Conversom

No es menos el vejamen que on aquella residencia padecen, porque ya parece que se ha hecho, o naturaleza, o sistema el mal tratamiento de los Indios al paso que se consideran y son tan útiles y necesarios. Por las diligencias practicadas ante los alcaldes de aquellos pueblos consta los servicios que sufren, las tareas indebidas con que son gravados, y demás abusos que experimentan. Preséntalas en debida forma el Superintendente (Supte.) porque aunque los indios tienen mal recomendada su verdad después de todo son unos infelices, y son los que llevan el trabajo y la peor parte en su humilde condición y la malicia para ponerse a cubierto de las resultas de su mal procedimiento contra unos naturales que tanta compasión merecen a S. M. Y a V. E. sobre dar diversos coloridos a los sucesos prácticos para que no tengan aceptación las quejas de su agravio.

No es esto lo que principalmente comprende el actual recurso: Redúcese a exponer la imposibilidad en que está constituída aquella Provincia para poder continuar con la Mitz de Potosí por la extrema decadencia a que han venido los Indios insuficientísimos para alternar, y deducir dicha Mita conforme a lo que tienen prescrito las Leyes, y Reales Ordenanzas en circunstancias en que aún prescindiendo de la distancia, y de la decadencia de los Indios hay copioso número de trabajadores establecidos en dicho Cerro de Potosí, con los que sin necesidad de las Mitas pueden laborearse las Minas, aún cuando estuviesen muy florecientes. 
Con este respecto las Ordenanzas comprendidas en el Lib. 2 F. 18 al Cap. 10 tratando de la conservación de estas Provincias dependiente de la labor, y beneficio de las Minas, y de la reservada necesidad que se tiene de la industria de los Indios, expresa S. M. con todo el mucho deseo que tiene de que sean relevadas en cuanto fuere posible, y que to haya repartimiento de elios interín los Mineros se proveen de negros, o Jornaleros valur:tarios; en el Cap 12 tratando del Mineral de 'Potosí manda que para expedir sus labores se procure por la mejor vía, y forma posible que se representan las Mitas de aquelles Indios que hubiere en el asiento y sus comarcas; en el Cap. 14 se encarga el puntual $y$ competente jornal que deba pagárseles, y el particular cuidado de su salud y buen tratamiento en lo espiritual y temporal, y que a los que fueren al servicio de aquellas Minas fuera del asiento se les paque la ida y vuelta.

En la Ordenanza 2 se repite al Cap. 2 el encargo de que los Mineros compren esclaves todo con respecto al alivio de los Indios, al Cap. 4 y al 8 se manda que se hagan poblaciones cerca de los asientos de Minas para que de esta suerte se haga más ligero el peso de las Mitas y repartimientos y se excuse traerlos de fuera. En el Cap. 5 se manda que la Mita y Repartimiento no pueda exceder de la séptima parte que hubiera en cada pueblo al tiempo de dicho Repartimiento parque no se debe atender a la más o menos saca de plata, y oro, como a la conservación de los Indios, y últimamente al Cap. 13 que se castígue a los caciques que enviaren a la segunda Mita a los Indios que fueron a la primera.

Estas Ordenanzas, son concordantes con las leyes del Lib. 6 F. 12 de la Recopilación de Indias: Según ellas en todas sus circunstancias se hace de justicia la pretensión de la Provincia de Canas y Canchis: La principalísima razónes por la decadencia de los Indios que reducidos a un número lastimoso no pueden tener descanso, y contra las mismas Ordenanzas van a la segunda Mita los que fueron a la primera, porque de otra suerte no pueden cumplirse. No se puede en la actualidad verificar la Mita en la Séptima parte porque apenas hay esta parte de la séptima como se podrá probar con poca diferencia jespecto de Indios originarios $\mathrm{y}$ en la competente edad para poder sostener el trabajo de la - Mita, que debe reducirse según suchúmero al tiempo del Repaftimiento conforme a la Ordenanza.

El Corregidor de la "Provinoia que ve, y expermenta las disminución y la dificultad que cuesta haber de enterar los Cacigues dicha Mita no dejaron de Informarlo siempre que se tenga por necesario: La distancia es un inconveniente gravísimo más de doscientas leguas de jornada y otras tantas de vuelta ofras tantas ocupan gravemente la consideración de la lástima, y hacen demostrable el inconveniente de la desolación de los Pueblos como la experiencia lo califica. Despídense o para morir, o para no volver más a su Patria; venden sus chozas, y sus muebles con unos pasajes dolorosos por la contracción de voluntad que tiene el Indio a su pueblo, a sus muebles, y a sus animales. Cargan con sus mujeres y sus hijos, y ya con sólo un indio Mitayo sale del Pueblo una familia entera que podía propagarlo, así entran en un camino de más de doscientas leguas de asperezas, de Ríos, Cardilleras, y de Punas que si a la ida lo pasan mal a la vuelta lo pasan peor si ellos como regularmente sucede no cautelan el trabajo con quedarse, y no volver.

Si en tiempo en que eran indispensables las Mitas por la inopia de trabajadores so atendía más a la conservación de los Indios, es ahora superior a la razán cuando las labores son menos; y es abundantísimo el número de trabajadores de que ha crecido el asiento de Potosí, para que aún esta distantísima Provincia no estuviese tan indigente de Indios se le relevase de dicha Mita conforme al expreso literal contexto de dichas Redies Ordenanzas que contraídas al caso presente obten los Mineros trabajar sus Minas con los muchos Indios que se han reducido y situado en el Cerro de Potosí que voluntalia. 
mente se alquilan, cesando así el inconveniente de la falta de operarios que hizo forzosa en los primeros tiempos la Mita: Bien conocen los Mineros esta razón pero quieren los Mitayos porque los tratan más que a esclavos, porque les pagan menos, y porque al pretexto de los privilegios de Mineros y por aparentar perjuicios en la extracción de los Metales conservan la Mita, para abusar del trabajo de los Indios, Y aunque las Provincias se aniquilen en daño, y menoscabo de los Reales Haberes de S. M. en los innumerables tributarios que pierde. Tan poseídos están los Mineros de la pronta contribución de ia Mita que teniendo obligación de pagar la ida y vuelta de los Mitayos que llaman leguage en nada menos piensan que en cumplirla tanto que por este Superior Gobierno en Decrets de 25 de Agosto de 1768 se mandó a pedimento de los Indios de la Provincia de Lampa entre otras cosas que el Sr. Gobernador de Potosí hiciese que los Mineros pagasen a los Mitayos el leguage. Esto no se consigue, y los miserables Indios emprenden un dilatads camino sin este auxilio que lo es debido de manera que aún en el caso de que estuviesen los Indios en aquel aumento que antes, siempre sería de justicia que se les pagase el leguago, y se les prestase el: auxilio de la jornada de ida y vuelta, sin la cual no podrían insidir a culpa si por falta de esta contribución dejaban de rendir la Mita en cuyos tórminos $A$ V. E. pide, y suplica que habiendo por presentados dichos poderes e Instrumentos se sirva declarar que los Indios de la expresada Provincia de Canas y Canchis no están obligados a la Mita de Potosi por la decadencia en que se hallan y demás justas causas que lleva el suplicante expuestas: Pide merced que con justicia espera alcanzar de la poderosa mano de V. E.

Excmo. Señor:

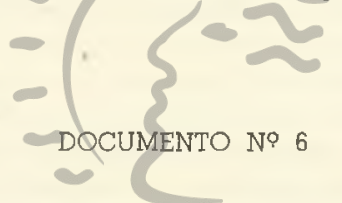

(fdo.) José Tupa Amaro.

He visto esta representación que por sí, y a nombre de los Caciques de la Provincia de Tinta, interpone a V.E. el que ló es de los Pueblos de Surimana, Pampamarca, y Tun gasuca Don José Tupa Amaro siempre que se:les liberte de la obligación de Mitar a la Villa de Potosí, respecto de los graves e irreparables perjulcios que en ello reciben, $Y$ hacer constar con los documentos que presentan.

Y lo que en el asunto debo informar a V. E. como me lo ordena por su Superior Decreto de 18 de Diciembre próximo pasado se reduce a que habiéndose promovido por el Superintendente la propia instancia en lo particular de los Pueblos de su cargo, expuso esla Confaduría en informe de 8 de agosto último, cuanto estimo conducente a la resolución de la materia de su contenido en que por una parte se verá el interés Real no menos que la utilidad pública con el laboreo de las Minas; y por otra el livio y conservación de los Indios expresando al mismo tiempo que por su entidad exigía se tomase resolución por la Superioridad de V. E. con acuerdo del Sr. Visitador General de este Reyno.

Aquella que fué representación particular, se extiende ya hoy por lo general de la Provincia comprobando con documentos los daños que reciben los que se destinan al servicio de dicha Mita, así por la inobservancia de lo prevenido por las Leyes, como por lo que reciben en su trato de los Mineros. Esta Contaduría no tiene cosa alguna que añadir al ya citado Informe: ignora la substanciación que se dió al mencionado Expediente y la determinación de V. E. por lo que en esta inteligencia resolvería lo que fuere más de su Superior agrado, de que para lo que ocurra en lo sucesivo, se tome razón en esta Contaduría de Retazas, y Enero 7 de 1778.

(fdo.) Juan José Leuros. 
Excmo. Señor:

Eil Oidor que hace de Protector General en vista de este expediente promovido por el Cacique Don José Tupa Amaro sobre que a los Indios de la Provincia de Tinta se liberto de la obligación de concurrir a la Mita de Potosí: Dice, que el Contador de Retazas en el Informe que hase con fecha 7 de Enero de este año expone haber sobre este mismo asunto anterior instancia pendiente, hecha por el referido Cacique la cual siendo V. E. servido podrá mandar se agregue, y que hecho corra de vista, o resolver lo que sea más de justicia. Lima, 7 de Abril de 1778.

\section{(fdo.) El Marquéa de Corpa.}

\section{FOLIO 173}

Lima, Abril 30 de 1778.

Agréguese el expediente que cita el Sr. Fis-

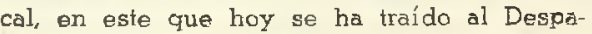
cho y hecho corra la vista.

Excmo. Seกีor:

El Protector General Interino reconocido el expediente promovido por Don José Tupa Amaro, Cacique de los Pueblos de Surimana y Pampamarca de la Provincia de Tinta siem. pre que a los Indios de los Pueblos do dicha Provincia se les liberte de la Mita de Potosí a que están obligados, y el expediente agregado con esta misma instancia dice que se ha substanciado con dictamen del Sr. Don José de Areche Visitador General de estos Reynos. En cuya atención parece que la nueva Instrucción, debe correr igual suerte poniéndose de su acertada dirección para que con ella se pueda, lograrse el feliz éxito que de manda la importancia de su materia, sobre que V. E. lo que fuere de justicia. Lima, Mayo 7 de 1778.

Excmo. Señor:

\section{Biblioteca de (fdo) El Marqués do soto Florido. "Jorge DodGuienso ino gnverso"}

El Oidor Físcal en vista del expediente promovido por Don José Tupa Amaro sobre que a los Indios de la Provincia de Tinta se les liberte de la obligación de concurrir a la Mita de Potosí dice que sobre el asunto se ha dado ya providencias por V. E. con acuerdo del Sr. Visitador General en el Superior Decreto de 25 de Setiembre del año próximo pasado, que podrá mandar se guardo y cumpla, librándose para ello las Ordenes que comprende, si aún no se ha verificado lo que no consta. Lima, Mayo 9 de 1778.

\section{(fdo.) El Marqués Corpa.}

\section{(A] margen se encuentra:)}

Lima, 20 de Mayo de 1778.

Respecto de que por el Decreto de veinte y cinco de Setiembre del año próximo pasado proveído con acuerdo del Sr. Visitador General de estos Reynos y a que se refie:e el Señor Fiscal en esta respiesta se halla expedida la prudencia correspondiente a extirpar los daños y perjuicios materia del presente Recurso: Guárdese y cúmplase dicho Su- 
perior Decreto, entendiéndose para lo general de la Provincia de Tinta; sáquese el test1 monio que está prevenido y remítasele al Sr. Don Jorge Escobedo Corregidor de la Villa de Potosí para que ponga en práctica su contexto acompañándosele con la respectiva carta. y esta providencia se hará saber al abogado.

(fdo.) Ureta.

\section{DOCUMENTO N: 8}

\section{Poder a favor de Túpac Amaru}

(Se sacó el Testimonio que se entregó al Poder Especial)

En la ciudad del Cuzco en cuatro días del mes de Octubre de mil setecientos setentiseis años. Ante mí el Escribano y competente número de testigos parecieron presentes Don Rámón Moscoso, cacique de los Ayllos de Illayoqua y Yanaoca, y Don Tomás de Soto caciqui del de Chicuayquo, reducidos en el Pueblo de Yanaoca Provincia de Tinta, a quienes conozco de que doy $f_{e}, \mathrm{y}$ otorgan ambos juntosi quedan sı poder cumplido bastante de que de derecho se requiere y se juzga necesario a Don José Tupa Amaro Cacique del Pueblo y Doctrina de Pampamarca especialmente, para que representando su propia persona, acción y derecho, siga, prosiga, fenezca, 4 acabe, la causa que tienen pendiente en el Real y Superior Gobierno de estos Reynos sobre que se liberten los Naturales de sus Ayllos de la pensión de la Mita que se despacha al Real Asiento de la Villa Imperial de Potosí. Y en esta razón presente escritos, escrituras y demás documentos que fueren necesarios e inste Informaciones que comprueben lo ineonveniente, que se sigue y perjudica a los miserables Indios, y practique dicho su Apoderado (que reside en la ciudad de Lima al presente) todos los otros actos y demås diligencias, quel judicialmente o extrajudicialmente sean precisos al buen éxito del interés de tanta importancia, que, hallándose presentes los oto:

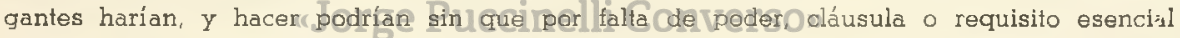
deje cosa por obrar de cuanto vien convenga. Que para ello, y lo incidente, y dependiente, anexo, y conveniente le dan este, con libre, general Administración y sin limitación alguna en lo expuesto, y con facultad de substituir, en quien, y las veces que le pareciere, revocando unos substitutos, y nombrando otros, que a todos relevan de costas según derecho A cuya firmeza, y lo que se obrare en viriud de este poder obligan sus personas, y bienes en la más bastante forma de derecho. En cuyo Testimonio así lo dijeron y otorgaron, y con intervención de Don Juan Antonio Rojas, y de Don Agustín José Becerra Intérpretes generales de esta dicha ciudad. sin embargo de que uno de los otorgantes, es español, y al otro aunque indio constantemente instruído, y ladino, y los dos lo firmaron con dichos intérpretes, siendo Testigos Don Martín Dolmos, Antonio de Bustamante y Mariano de la Banda presentes.-Ramón Moscoso.--Juan Antonio Rojas.-José Agustín Chacón y Becerra.-Tomás Soto.-Ante mí José de Palacios, Escribano de Su Magestad.

(fdo.) José de Palacios, Escribano de S. M. 